\title{
Article
}

\section{Gender specific ACL loading patterns during the fencing lunge: Implications for ACL injury risk}

Sinclair, Jonathan Kenneth and Bottoms, Lindsay

Available at http://clok.uclan.ac.uk/23119/

Sinclair, Jonathan Kenneth ORCID: 0000-0002-2231-3732 and Bottoms, Lindsay (2018) Gender specific ACL loading patterns during the fencing lunge: Implications for ACL injury risk. Science \& Sports . ISSN 0765-1597

It is advisable to refer to the publisher's version if you intend to cite from the work. http://dx.doi.org/10.1016/j.scispo.2018.05.005

For more information about UCLan's research in this area go to http://www.uclan.ac.uk/researchgroups/ and search for < name of research Group>.

For information about Research generally at UCLan please go to http://www.uclan.ac.uk/research/

All outputs in CLoK are protected by Intellectual Property Rights law, including Copyright law. Copyright, IPR and Moral Rights for the works on this site are retained by the individual authors and/or other copyright owners. Terms and conditions for use of this material are defined in the policies page.

\section{CLoK}

Central Lancashire online Knowledge www.clok.uclan.ac.uk

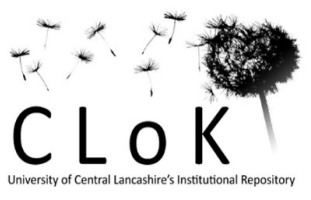


injury risk

$\underline{\text { Sexe spécifique ACL patrons de chargement lors de la fente de l'escrime : Implications }}$ pour le risque de blessure des ACL.

6 Keywords: Biomechanics, ACL, fencing, sport.

7

\section{$8 \quad$ Abstract}

9 Purpose: Determine whether gender differences in ACL loading linked to the aetiology of 10 injures are evident during the fencing lunge.

11 Materials \& Methods: ACL loading was obtained from ten male and ten female fencers

12 using an eight-camera 3D motion capture system and force platform data as they completed 13 simulated lunges. Gender differences in ACL loading parameters were examined using 14 independent samples t-tests.

15 Results: Peak ACL load and instantaneous rate of loading were significantly larger in female fencers $(6.21 \mathrm{~N} / \mathrm{kg} \& 511.18 \mathrm{~N} / \mathrm{kg} / \mathrm{s})$ in comparison to males $(4.04 \mathrm{~N} / \mathrm{kg} \& 378.77 \mathrm{~N} / \mathrm{kg} / \mathrm{s})$.

17 Conclusions: This investigation indicates that female fencers may be at increased risk from

18 ACL pathologies. Future analyses should seek to investigate and implement strategies aimed 19 at reducing ACL loading in female fencers.

\section{Résumé:}


22 Objectif: Déterminer si les différences entre les sexes au sein de l'ACL loading liée à

23 l'étiologie des blessures sont évidentes lors de l'escrime sur une jambe.

24 Méthodes: Le chargement a été obtenu à partir de la liste de dix hommes et dix femmes tireurs à l'aide d'un huit-clos 3D motion capture system et forcer la plate-forme les données comme ils ont réalisé une simulation se jette. Les différences entre les sexes au sein de l'ACL Chargement des paramètres ont été examinés à l'aide des tests $\mathrm{t}$ sur des échantillons indépendants.

Résultats: Liste de contrôle de pointe et de charge taux instantané de chargement était significativement plus élevée chez les tireurs $(6.21 \mathrm{~N} / \mathrm{kg}$ et $511.18 \mathrm{~N} / \mathrm{kg} / \mathrm{s})$ par rapport aux hommes $(4.04 \mathrm{~N} / \mathrm{kg}$ et $378.77 \mathrm{~N} / \mathrm{kg} / \mathrm{s})$.

Conclusion: Cette enquête indique que les tireurs peuvent être à risque accru de pathologies d'ACL. Les analyses futures pourraient chercher à étudier et mettre en œuvre des stratégies visant à réduire la charge ACL dans les tireurs.

\section{Introduction}

37 Fencing is an Olympic sport which requires the fencer to strike an opponent with their sword to score a hit (1). Fencing represents a high intensity and intermittent discipline that necessitates short bouts of high intensity exercise and periods of relatively low intensity activity. Bounces, steps and lunges occur frequently during the competition for the purposes of defence and attack, which place high demands the musculoskeletal system (2). 
43 Epidemiological analyses have documented that injuries and pain associated with fencing

44 training/ competition were apparent in $92.8 \%$ of fencers, with the majority of these injuries being experienced in the lower extremities (3). Harmer (3) showed that the knee was the most commonly injured musculoskeletal site in fencers, accounting for $19.6 \%$ of all pathologies; with particular concern relating to the anterior cruciate ligament (ACL). The data of Mountcastle et al., (4) supports this notion indicating that the ACL was a common injury location in military recruits involved in fencing training/ competition.

The ACL is one of the 4 predominant ligaments that are effective in providing stability to the knee joint. The primary function of the ACL is to resist anterior tibial translation, providing $87 \%$ of the total restraining force at $30^{\circ}$ of knee flexion (5). The ACL also prevents excessive knee extension, knee adduction and abduction movements, and resists internal rotation of the tibia (6). Injuries to the ACL are debilitating, cause long term cessations from training/ competition and may ultimately be career threatening as current treatment modalities do always successfully return athletes to their previous levels of functionality (7). ACL injuries are also associated with long term health implications, with athletes being up to 10 times more likely to develop early-onset degenerative knee osteoarthritis in relation to non-injured controls (8), leading not only to a reduction in sports activity but also chronic incapacity in later life (9). ACL injuries traditionally necessitate surgical intervention, followed by a significant and aggressive period of rehabilitation. Gottlob et al., (10) determined that over 175,000 ACL surgeries are performed each year in the US with directly associated costs of over $\$ 2$ billion. 
66 The majority of ACL injuries (72\%) are non-contact in nature, in that injury occurs without

67 physical contact between athletes (11). Mechanically, ACL injuries manifest when excessive

68 loading is experienced by the ACL itself (12). Non-contact ACL injuries habitually occur at the point of foot strike with the knee close to full extension in athletic disciplines where sudden decelerations, landing and pivoting manoeuvres are repeatedly performed (13). It has been demonstrated that most non-contact ACL injuries occur in activities that involve singlelimb decelerations (11). The lunge is the most frequently used attack in fencing (14). However, the front leg must produce a rapid deceleration action on landing to stabilize the fencer (15), thus it appears that the lunge movement may be the movement that placers fencers at greatest risk from ACL pathology.

Whilst male and female fencers often train concurrently, fencing competitions are gender specific. Importantly, Harmer, (3) showed that female fencers had a $35 \%$ greater risk for time-loss injuries in relation to males. Furthermore, ACL injuries are renowned for being prevalent in female athletes, with an incidence rate in the region of 4-10 times that noted in males (16). The enhanced risk for ACL injury in female athletes has led to a significant amount of research attention focussed on the mechanical factors responsible for the gender disparity in the rate of ACL injuries. Gender differences in lower body mechanics in fencing have received only limited attention in biomechanical literature. Sinclair \& Bottoms, (14) examined gender differences in lower extremity kinematics during the fencing lunge. Their findings showed that females produced significantly greater knee abduction and hip adduction of the lead limb during the lunge. Furthermore, Sinclair et al., (17) investigated gender specific loading of the Achilles tendon during the lunge movement. They demonstrated that males exhibited significantly greater Achilles tendon loading in comparison to females. However, gender differences in ACL loading during the fencing 
91 lunge have yet to be explored, thus gender specific risk for ACL injury in fencers is currently

92 unknown.

93

94 Therefore, the aim of the current investigation was to determine whether gender differences

95 in ACL loading linked to the aetiology of injures are evident during the fencing lunge.

96 Research of this nature may provide important clinical information regarding potential ACL

97 injury risk in fencers.

98

99 Methods

100 Participants

101

Ten male participants and ten female participants volunteered to take part in this investigation

102

(all were right hand dominant). All were injury free at the time of data collection and provided written informed consent in accordance to guidelines outlined in the declaration of 104 Helsinki. Participants were active competitive fencers who engaged in training a minimum of 1053 training sessions per week. The mean characteristics of the participants were males; age 106 $26.22 \pm 3.99$ years, height $1.79 \pm 0.04 \mathrm{~m}$ and mass $76.21 \pm 4.21 \mathrm{~kg}$ and females; age $25.47 \pm$ 4.48 years, height $1.67 \pm 0.05 \mathrm{~m}$ and mass $63.20 \pm 3.05 \mathrm{~kg}$. The procedure was approved by the University of Central Lancashire ethics committee (REF: STEMH 676) and the data 
112 Participants were required to complete 5 lunges hitting a dummy with their weapon whilst returning to a starting point (pre-determined by each participant prior to the commencement of data capture) following each trial to control lunge distance. In addition to striking the dummy with their weapon participants also made contact with a force platform (Kistler, Kistler Instruments Ltd., Alton, Hampshire) embedded in the floor (Altrosports 6mm, Altro Ltd,) of a biomechanics laboratory with their right (lead) foot. The starting point for the movement was adjusted and maintained for each participant. Kinematics and ground reaction force data were synchronized using an analogue to digital interface board. The lunge movement was delineated as the period from foot contact (defined as $>20 \mathrm{~N}$ of vertical force applied to the force platform) to the instance of maximum knee flexion (14).

An eight camera motion analysis system (Qualisys ${ }^{\mathrm{TM}}$ Medical AB, Gothenburg, Sweden) captured kinematic data. Calibration of the motion analysis system was performed before each data collection session. Only calibrations which produced average residuals of less than $0.85 \mathrm{~mm}$ for each camera for a $750.5 \mathrm{~mm}$ wand length and points above 4000 were accepted prior to data collection.

To define the segment co-ordinate axes of the right foot, shank and thigh, retroreflective markers were placed unilaterally onto the 1st metatarsal, 5th metatarsal, calcaneus, medial and lateral malleoli, medial and lateral epicondyles of the femur. To define the pelvis segment further markers were positioned onto the anterior (ASIS) and posterior (PSIS) superior iliac spines. Carbon fiber tracking clusters were positioned onto the shank and thigh segments. The foot was tracked using the 1st metatarsal, 5th metatarsal and calcaneus markers and the pelvis using the ASIS and PSIS markers. The centers of the ankle and knee 
joints were delineated as the mid-point between the malleoli and femoral epicondyle markers

137 (18; 19), whereas the hip joint centre was obtained using the positions of the ASIS markers

138

139

140

(20). Static calibration trials (not normalized to static trial posture) were obtained for the anatomical markers to be referenced in relation to the tracking markers/ clusters. The $\mathrm{Z}$ (transverse) axis was oriented vertically from the distal segment end to the proximal segment end. The Y (coronal) axis was oriented in the segment from posterior to anterior. Finally, the $\mathrm{X}$ (sagittal) axis orientation was determined using the right hand rule and was oriented from medial to lateral.

\section{Processing}

Dynamic trials were processed using Qualisys Track Manager and then exported as C3D files. GRF and marker data were filtered at $50 \mathrm{~Hz}$ and $15 \mathrm{~Hz}$ respectively using a low-pass Butterworth 4th order filter and processed using Visual 3-D (C-Motion, Germantown, MD, USA). Joint moments were computed using Newton-Euler inverse-dynamics, allowing net knee joint moments to be calculated. Angular kinematics were calculated using an XYZ (sagittal, coronal and transverse) sequence of rotations (21). To quantify knee joint moments segment mass, segment length, ground reaction force and angular kinematics were utilized.

A musculoskeletal modelling approach was utilized to quantify ACL loading during the lunge movement. To accomplish this we firstly had to quantify the tibial-anterior shear force (TASF), which was undertaken using a modified version of the model described in detail by Devita \& Hortobagyi, (22). Our model differed only in that gender specific estimates of 
posterior tibial plateau slope (23), hamstring-tibia shaft angle (24) and patellar tendon-tibia shaft angle (25) were utilized.

ACL loading was determined as the sum of ACL forces caused by the TASF, transverse plane knee moment, and transverse plane knee moment in accordance with $\mathrm{EQ}[1]$.

$\mathrm{EQ}[1]-\mathbf{A C L}$ load $=(F 100 / 100 * \mathrm{TASF})+($ F10TV $/ 10 *$ transverse plane knee moment $)+$ $($ F10CR / $10 *$ transverse plane knee moment $)$

The components of EQ[1] were obtained using the data described by Markolf et al., (26), who examined ACL forces in vitro when a $100 \mathrm{~N}$ TASF (F100) was applied to cadaver knees from $0-90^{\circ}$ of knee flexion. ACL forces were also measured when additional torques of 10 $\mathrm{Nm}$ in the coronal $($ F10CR $)$ and transverse (F10TV) planes were combined with the $100 \mathrm{~N}$ TASF from $0-90^{\circ}$ of knee flexion.

All force parameters were normalized by dividing the net values by body mass $(\mathrm{N} / \mathrm{kg})$. From the musculoskeletal models indices of peak ACL and TASF forces were extracted. In addition ACL and TASF instantaneous load rates $(\mathrm{N} / \mathrm{kg} / \mathrm{s})$ were quantified as the peak increase in force between adjacent data points. In addition we also calculated the ACL impulse N/kg.s) during the lunge movement by multiplying the ACL load by the duration over which the movement occurred. 
181 Descriptive statistics of means, standard deviations (SD) and 95\% confidence intervals (95\%

182 CI) were calculated. Gender differences in ACL loading parameters were examined using 183 independent samples t-tests with significance accepted at the $\mathrm{P} \leq 0.05$ level (27). Effect sizes were quantified using partial eta squared $\left(\mathrm{p \eta}^{2}\right)$. Shapiro-Wilk tests confirmed that the data were normally distributed in all cases. All statistical procedures were conducted using SPSS v23 (SPSS Inc., Chicago, IL, USA).

\section{Results}

Table 1 and figure 1 present the gender differences in ACL loading during the fencing lunge movement. The results indicate that ACL loading parameters were significantly influenced by gender.

Peak TASF was found to be significantly $\left(\mathrm{t}(9)=2.65, \mathrm{P}<0.05, \mathrm{p}^{2}=0.29\right)$ larger in female fencers in relation to males (Table 1; Figure 1a). In addition peak ACL was found to be significantly $\left(\mathrm{t}(9)=2.65, \mathrm{P}<0.05, \mathrm{p}^{2}=0.35\right)$ larger in females in comparison to males (Table 1; Figure 1b). 
201 TASF instantaneous load rate was also found to be significantly $\left(\mathrm{t}(9)=2.65, \mathrm{P}<0.05, \mathrm{p} \eta^{2}=\right.$ 202 0.24) higher in female fencers in compared to males (Table 1). ACL instantaneous load rate

203

204

206

207

208

209

210

211

212

214

215

216

217

219

220

221

222

was similarly shown to be significantly $\left(\mathrm{t}{ }_{(9)}=2.65, \mathrm{P}<0.05, \mathrm{p}^{2}=0.26\right)$ larger in females in comparison to males (Table 1). Finally, it was demonstrated that ACL impulse was significantly $\left(\mathrm{t}{ }_{(9)}=2.65, \mathrm{P}<0.05, \mathrm{p}^{2}=0.38\right)$ greater in females in relation to male fencers (Table 1).

\section{Discussion}

The aim of this investigation was to investigate gender differences in ACL loading during the fencing lunge. To the authors knowledge this study represents the first quantitative examination of ACL loading during fencing specific manoeuvres. Research of this nature may provide important clinical information regarding potential ACL injury risk in fencers.

The primary observation from the current study is that ACL loading parameters were found to be significantly larger in female fencers. Females exhibit distinct knee mechanics during deceleration/ landing tasks, involving reduced knee flexion, increased hip rotation/ adduction and knee valgus (12). Female athletes are regarded as being over reliant on the anterior kinetic chain due to diminished neuromuscular control in the posterior chain (28). The knee posterior kinetic chain musculature, in particular the hamstring group are considered a synergist with the ACL and serve to mediate ATSF by pulling the tibia posteriorly (28). This may help clarify the mechanism by which increases in ACL loading were observed in female fencers as knee ligament forces are strongly influenced by the ATSF (29). The lunge is renowned as one of the primary attacking mechanisms in fencing (14), thus the observations 
from the current investigation may have potential clinical relevance regarding the aetiology of injury in female fencers. Mechanically, ACL injuries during dynamic tasks occur when excessive loading is experienced by the ACL itself (12). This study therefore provides insight into the increased incidence of ACL injuries in female athletes and also shows that female fencers may be at increased risk from ACL pathologies when performing the lunge movement.

The current study represents the first to quantitatively evidence that female fencers exhibit greater ACL loading in relation to males. ACL injuries are one of the most common pathologies in athletic populations (30) and female athletes are considered to be at much greater risk from this injury in relation to males (16). Thus it is important that training/ conditioning adaptations be incorporated by fencing coaches which are designed to decrease the risk from ACL injuries in females. Neuromuscular deficiencies are regarded as a key modifiable risk factor for ACL injuries, and controlling the magnitude of ACL loading through preventive neuromuscular training has been demonstrated as an effective intervention for the modification of ACL injury risk (31). Therefore it is strongly recommended that specific neuromuscular training protocols focussed on the muscles of posterior kinetic chain be implemented for female fencers in order to attenuate their risk from ACL injury.

A potential limitation of the current investigation is that ACL loading was quantified using a musculoskeletal modelling approach. This was necessary given the impracticalities and ethical concerns regarding the collection of ligament loading in vivo during high intensity activities. However, although the musculoskeletal approach utilized in this study is associated with good face validity (32); modelling approaches are subject to mathematical assumptions 
to the current study is that the stiffness and frictional properties of the laboratory surface are

likely to be distinct from those experienced when performing on a traditional fencing piste

(33). Therefore, ACL loading may have differed had participants performed on a fencing

specific surface. As such it is strongly recommended that this study be repeated using a field

In conclusion, whilst gender differences in lower extremity biomechanics have received limited attention within clinical literature, the effects of gender on ACL loading parameters linked to the aetiology of ACL injuries has not been explored. As such the current study adds to the current literature base in the field of clinical biomechanics by providing a comprehensive analysis of gender specific loading patterns experienced during the fencing lunge. The findings from this investigation showed that female fencers experienced significantly larger ACL loading parameters than males during the lunge movement. Given the association between ACL loading and ACL injury risk, this investigation firstly provides insight into the high incidence of ACL injuries in female athletes and secondly indicates that female fencers may be at increased risk from ACL pathologies. Future analyses should seek to investigate and implement strategies aimed at reducing ACL loading in female fencers.

\section{References}

1. Turner, A., Miller, S., Stewart, P., Cree, J., Ingram, R., Dimitriou, L., \& Kilduff, L. (2013). Strength and conditioning for fencing. Strength \& Conditioning Journal, 35, 
2. Bottoms, L., Sinclair, J., Gabrysz, Gabrysz, U., \& Price, MJ. (2011). Physiological responses and energy expenditure to simulated epee fencing in elite female fencers. Serbian journal of sports sciences, 5, 17-20.

3. Harmer, P.A. (2008). Getting to the point: injury patterns and medical care in competitive fencing. Current Sports Medicine Reports, 7, 303-307.

4. Mountcastle, S.B., Posner, M., Kragh, J.F., \& Taylor, D.C. (2007). Gender differences in anterior cruciate ligament injury vary with activity epidemiology of anterior cruciate ligament injuries in a young, athletic population. The American Journal of Sports Medicine, 35, 1635-1642.

5. Butler, D. L., Noyes, F. R., \& Grood, E. S. (1980). Ligamentous restraints to anteriorposterior drawer in the human knee. Journal of Bone \& Joint Surgery, 62, 259-270.

6. Liu-Ambrose, T. (2003). The anterior cruciate ligament and functional stability of the knee joint. BC Med J, 45, 495-499.

7. Ardern, C.L., Webster, K.E., Taylor, N.F., \& Feller, J.A. (2011). Return to sport following anterior cruciate ligament reconstruction surgery: a systematic review and meta-analysis of the state of play. British Journal of Sports Medicine, 45, 596-606.

8. Øiestad, B.E., Engebretsen, L., Storheim, K., \& Risberg, M.A. (2009). Knee osteoarthritis after anterior cruciate ligament injury a systematic review. The American Journal of Sports Medicine, 37, 1434-1443.

9. Ajuied, A., Wong, F., Smith, C., Norris, M., Earnshaw, P., Back, D., \& Davies, A. (2014). Anterior cruciate ligament injury and radiologic progression of knee osteoarthritis: a systematic review and meta-analysis. The American Journal of Sports Medicine, 42, 2242-2252. 

of anterior cruciate ligament reconstruction in young adults. Clinical Orthopaedics and Related Research, 367, 272-282.

11. Boden, B. P., Torg, J. S., Knowles, S. B., \& Hewett, T. E. (2009). Video analysis of anterior cruciate ligament injury abnormalities in hip and ankle kinematics. The American Journal of Sports Medicine, 37, 252-259.

12. Smith, H. C., Vacek, P., Johnson, R. J., Slauterbeck, J. R., Hashemi, J., Shultz, S., \& Beynnon, B. D. (2012). Risk factors for anterior cruciate ligament injury: a review of the literature_-part 1: neuromuscular and anatomic risk. Sports Health, 4, 69-78.

13. Olsen, O. E., Myklebust, G., Engebretsen, L., \& Bahr, R. (2004). Injury mechanisms for anterior cruciate ligament injuries in team handball a systematic video analysis. The American Journal of Sports Medicine, 32, 1002-1012.

14. Sinclair, J., \& Bottoms, L. (2013). Gender differences in the kinetics and lower extremity kinematics of the fencing lunge. International Journal of Performance Analysis in Sport, 13, 440-451.

15. Sinclair, J., Bottoms, L., Taylor, K., \& Greenhalgh, A. (2010). Tibial shock measured during the fencing lunge: the influence of footwear. Sports Biomechanics, 9, 65-71.

16. Arendt, E. A., Agel, J., \& Dick, R. (1999). Anterior cruciate ligament injury patterns among collegiate men and women. Journal of Athletic Training, 34, 86.

17. Sinclair, J., \& Bottoms, L. (2014). Gender differences in the Achilles tendon load during the fencing lunge. Baltic Journal of Health and Physical Activity, 6, 199-204.

18. Graydon, R. W., Fewtrell, D. J., Atkins, S., \& Sinclair, J. K. (2015). The test-retest reliability of different ankle joint center location techniques. Foot and Ankle Online Journal, 5, 1-9. 
19. Sinclair, J., Hebron, J., \& Taylor, P. J. (2015). The test-retest reliability of knee joint center location techniques. Journal of Applied Biomechanics, 31, 117-121.

20. Sinclair, J., Taylor, P. J., Currigan, G., \& Hobbs, S. J. (2014). The test-retest reliability of three different hip joint centre location techniques. Movement \& Sport Sciences, 7, 31-39.

21. Sinclair, J., Taylor, P. J., \& Bottoms, L. (2013). The appropriateness of the helical axis technique and six available cardan sequences for the representation of 3-D lead leg kinematics during the fencing lunge. Journal of Human Kinetics, 37, 7-15.

22. DeVita, P., \& Hortobagyi, T. (2001). Functional knee brace alters predicted knee muscle and joint forces in people with ACL reconstruction during walking. Journal of Applied Biomechanics, 17, 297-311.

23. Hohmann, E., Bryant, A., Reaburn, P., \& Tetsworth, K. (2011). Is there a correlation between posterior tibial slope and non-contact anterior cruciate ligament injuries?. Knee Surgery, Sports Traumatology, Arthroscopy, 19 109-114.

24. Lim, B. O., Lee, Y. S., Kim, J. G., An, K. O., Yoo, J., \& Kwon, Y. H. (2009). Effects of sports injury prevention training on the biomechanical risk factors of anterior cruciate ligament injury in high school female basketball players. The American journal of sports medicine, 37, 1728-1734.

25. Nunley, R. M., Wright, D., Renner, J. B., Yu, B., \& Garrett Jr, W. E. (2003). Gender comparison of patellar tendon tibial shaft angle with weight bearing. Research in Sports Medicine, 11, 173-185.

26. Markolf, K. L., Burchfield, D. M., Shapiro, M. M., Shepard, M. F., Finerman, G. A., \& Slauterbeck, J. L. (1995). Combined knee loading states that generate high anterior cruciate ligament forces. Journal of Orthopaedic Research, 13, 930-935. 
27. Sinclair, J., Taylor, P. J., \& Hobbs, S. J. (2013). Alpha level adjustments for multiple dependent variable analyses and their applicability-a review. International Journal of Sports Science \& Engineering, 7, 17-20.

28. Hewett, T. E., Ford, K.R.H., \& Myer, G.D. (2010). Understanding and preventing ACL injuries: current biomechanical and epidemiologic considerations-update 2010. North American Journal of Sports Physical Therapy, 5, 234-251.

29. Shelburne, K. B., Pandy, M. G., \& Torry, M. R. (2004). Comparison of shear forces and ligament loading in the healthy and ACL-deficient knee during gait. Journal of Biomechanics, 37, 313-319.

30. Kiapour, A.M., \& Murray, M.M. (2014). Basic science of anterior cruciate ligament injury and repair. Bone and Joint Research, 3, 20-31.

31. Mandelbaum, B. R., Silvers, H. J., Watanabe, D. S., Knarr, J. F., Thomas, S. D., Griffin, L. Y., \& Garrett, W. (2005). Effectiveness of a neuromuscular and proprioceptive training program in preventing anterior cruciate ligament injuries in female athletes 2-year follow-up. The American Journal of Sports Medicine, 33, 1003-1010.

32. Dai, B, \& Yu, B. (2012). Estimating ACL force from lower extremity kinematics and kinetics. 36th annual meeting of the American Society of Biomechanics Gainesville, Florida, 253-254.

33. Greenhalgh, A., Bottoms, L., \& Sinclair, J. (2013). Influence of surface on impact shock experienced during a fencing lunge. Journal of Applied Biomechanics, 29, 463467.

\section{Figure labels}


366 Figure 1: a. Tibial-anterior shear force (TASF) and b. ACL load as a function of gender $367 \quad($ Black $=$ female $\&$ grey dash $=$ male $)$. 